\title{
1. filosofia educativa de Eugenio María de Hostos
}

\section{Roberto Gutiérrez Laboy}

Universidade de Porto Rico

Não é suficiente ensinar conhecimento, tem que ensinar a adquiri-lo; não é suficiente dar ciência feita; é necessário ensinar a produzi-la; não é suficiente se sujeitar ou sujeitar ao ensino de um método; é necessário ensinar a usá-lo. Em uma palavra: não é suficiente ensinar a conhecer; é necessário ensinar a raciocinar.

Hostos, 1969 , v. 13, p. 52

O porto-riquenho Eugenio María de Hostos (1839-1903) é um dos principais filósofos latino-americanos do século XIX ao lado do brasileiro Tobias Barreto, do argentino Juan Bautista Alberdi, do cubano Enrique José Varona, do peruano Manuel González Prada, do chileno Francisco Bilbao, do venezuelano Andrés Bello e do equatoriano Juan Montalvo, dentre outros.

A vida e obra de Hostos, tanto intelectual quanto política e social, através de Nossa América (como dizia o cubanoJosé Martí) tem sido reconhecida e celebrada internacionalmente. Isso em razão da notável produção intelectual que o filósofo gerou nas áreas da 
filosofia, pedagogia, sociologia, direito, história, letras, política e geografia. Além de uma obra política e educativa que vai desde seu destacado esforço pela consecução da independência de Porto Rico e Cuba até sua relevante reforma da educação em países como Chile e a República Dominicana. Por essa razão, escolas, ruas, universidades, prédios públicos e até cidades de vários países têm seu nome. Os comentários de importantes intelectuais assim o corroboram.

Foi nomeado "Mestre de mestres" pelo romancista guatemalteco e Prêmio Nobel de Literatura Miguel Ángel Asturias. O erudito dominicano Pedro Henríquez Ureña considerou-o "pensador profundo e soberbo". O filósofo e teólogo norte-americano Edgar S. Brightman denominou-o "O Fichte da América Espanhola”. A Prêmio Nobel de Literatura chilena Gabriela Mistral chamou-o "prócer moral". O filósofo mexicano Leopoldo Zea viu-o "como a consciência latino-americana”. José Luis Abellán - filósofo espanhol distinguiu-o como "um homem de dimensão continental”.

Além disso, Hostos tem sido considerado por eminentes intelectuais internacionais como o fundador ou promotor na América de várias disciplinas. É citado, por exemplo, como o iniciador da sociologia, da pedagogia da liberação, como um dos primeiros ensaístas e como pioneiro da bioética (Gutiérrez Laboy, 2010, p. 124-125).

Então, por que um homem que tanto fez pela América Latina não é muito conhecido no Brasil? Ainda mais, eu tenho a impressão de que a maioria dos leitores deste artigo, para não dizer todos, nunca ouviram falar dele. Por conseguinte, temos de nos questionar o porquê desse fato.
A resposta imediata é que a comunicação entre a América que fala espanhol e a que fala português não tem sido a melhor até agora. É difícil de compreender, mas a realidade é que o desapego entre as duas Américas, mais que um assunto de distância territorial, é um problema de desvinculação sociocultural.

Muitos autores têm se referido a esse tema. As razões são muitas e diversas.José Murilo de Carvalho elucida que "A elite brasileira sempre fez questão de marcar a especificidade do Brasil em relação a esses países. No século XIX, os países hispânicos eram vistos como exemplo negativo de violência política, de caudilhismo, de barbárie" (1998, p. 273). Tentando compreender o motivo subjacente, Priscila Ribeiro Dorella anota que "há um significativo preconceito que podemos perceber no pensamento brasileiro, ao longo dos séculos XIX e XX, sobre a América Hispânica como um lugar menos desenvolvido e mais caótico que o Brasil” (2006, p. 59). O assunto chega ao ponto em que intelectuais, políticos, jornalistas e educadores se perguntam se o Brasil é ou não parte da América Latina (Dorella, 2006, p. 61). Dorella chega à conclusão de que "o discurso nacionalista brasileiro obstaculizou o conhecimento mais profundo sobre a América Hispânica. O nacionalismo, ao considerar a língua, a cultura e a religião como os principais identificadores da nação, percebia a América Hispânica como uma ameaça às especificidades brasileiras" (idem, p. 63).

Do mesmo modo, em 2003, o jornalista, ensaísta e narrador paulistano Rodrigo Gurgel escreveu o artigo "O Brasil precisa descobrir a cultura latino-americana”, em que expõe sua preocupação em torno de tão nevrálgico tópico. 
Gurgel inicia sua exposição arguindo que "O Brasil sempre esteve de costas para o restante da América Latina, com os olhos postos, numa incompreensível nostalgia, no caminho do Atlântico que leva aos países do hemisfério norte". E continua com a seguinte afirmação:

Nunca ousamos uma política exterior propositiva. Nunca tivemos a coragem de erguer os olhos para um ponto além daquele vislumbrado pelos Estados Unidos da América do Norte. Jamais nos atrevemos a considerar os países latino-americanos como parceiros efetivos e incontestes para a construção de um continente capaz de, unido em seus pontos fortes e em suas dificuldades, enfrentar o imperialismo norte-americano de maneira altiva, responsável e independente.

Ainda mais importante no contexto da minha ponderação, no seu artigo ele escreve que:

Não há entre nós, por exemplo, uma única tradução de dois dos mais lúcidos cérebros latino-americanos: o dominicano Pedro Henríquez Ureña e o porto-riquenho Eugenio María de Hostos. De Ureña ainda é possível encontrar uma coletânea de ensaios - publicados na Colección Archivos, infelizmente estagnada e duas ou três obras importadas pela Fondo de Cultura, do México, que possui uma representação em São Paulo. Mas de Eugenio María de Hostos seria inútil qualquer busca, mesmo em castelhano, restando-nos somente a internet.
Mas, como toda moeda tem dois lados, devo fazer referência ao escritor brasileiro Silvio Julio de Albuquerque Lima, o qual dedicou parte de sua vida para que o povo brasileiro compreendesse melhor as outras nações de Nossa América. Faz-se necessário, também, citar Priscila Ribeiro Dorella, que pesquisou magistralmente o tema numa dissertação. De fato, ela ilustra o empenho de Lima nesse particular e aclara que "O autor reconhecia o esforço que haveria de ser feito para que ocorresse o reconhecimento positivo em relação à América Hispânica. Eugenio María de Hostos, por exemplo" (2006, p. 64). A acadêmica prossegue discorrendo sobre a relevância de Hostos, citando do livro Escritores antilhanos de Lima:

Virtuoso, cavalheiresco, patriota, americanista, educador, polígrafo, quem já o leu no Brasil? Além disto, se lhe gritarmos alto o valor, quantos nos desmentirão, dizendo impossível que Porto Rico tenha sido berço de intelectuais que se meçam com os nossos? De norte a sul da América, os que falam castelhano e os que falam inglês consideram-no mestre, espelho, farol dos talentos mais respeitáveis. (idem, ibidem)

Contudo, pelo divulgado até aqui, não quer dizer que Hostos seja um total desconhecido entre os intelectuais brasileiros, já que alguns estudiosos têm se ocupado de sua vida e obra. Como constatação, pode consignar-se o livro do falecido professor da Universidade de São Paulo Luis Amador Sánchez, Cuatro estudios: Hostos, Martí, Rodó, Blanco-Fombona (São Paulo: Faculdade de Filosofia, Ciências e Letras, 1958) e o estudo "Perspectivas interpretativas 
do Caribe e o antilhanismo de Eugenio María de Hostos" (no livro Caribe: sintonias e dissonâncias, organizado por Olga Cabrera e Jaime de Almeida, Editora CECAB, 2004), dos professores Eugenio Rezende de Carvalho e Giselle Garcia de Oliveira. ${ }^{2}$

Eugenio María de Hostos nasceu em 11 de janeiro de 1839 na cidade de Mayagüez da ilha caribenha de Porto Rico. Na Universidade Central de Madri, iniciou a carreira de direito e filosofia e letras, estudos que não completou, descontente com o método de ensino da época. $\mathrm{Na}$ Espanha, defendeu a causa da República, e uma vez que os republicanos obtiveram o poder, foi-lhe oferecido o governo de Barcelona, mas ele o rejeitou. Entre 1868 e 1869, morou em Paris; já em 1870 vai para Nova York e nesse ano, justamente, começa sua peregrinação pelos povos de Nossa América: Colômbia, Peru, Chile, Ar gentina, Brasil, República Dominicana e Venezuela. Em muitos desses países, Hostos dedicou-se não somente a escrever na imprensa local - posto que se comprometesse com seus problemas -, mas também a apontar ideias para procurar sua solução. No Peru, chamou a atenção para a exploração dos chineses. Foi reformador da educação no Chile e República Dominicana. Na Argentina, sugeriu a construção de um trem transandino que aproximasse o país do Chile. Foi reitor do Liceu de Chillán e do Liceu "Miguel Luis Amunátegui", ambos no Chile, e professor da Universidade de Santiago.

Oliveira (professora do Colégio Estadual Santa Luzia e da Faculdade Alfredo Nasser, GO) é também autora da dissertação de mestrado O antilhanismo de Eugenio María de Hostos, apresentada na Faculdade de Ciências Humanas e Filosofia da Universidade Federal de Goiás em 2006.
Na República Dominicana, foi fundador e diretor da Escola Normal, assim como professor da Universidade Autônoma de Santo Domingo, onde ministrou aulas de direito internacional, penal e constitucional, economia política e moral social. De fato, nessa universidade lecionou sociologia, sendo a primeira vez que esse curso se ministrava na América Latina. Na área da política, seu objetivo sempre foi liberar Porto Rico e Cuba, as últimas colônias espanholas no "Novo mundo", assim como organizar a Confederação Antilhana. Faleceu na República Dominicana em 11 de agosto de 1903.

Entre as obras de maior importância no acervo cultural hostosiano encontra-se o romance $A$ peregrinação do Bayoán e os ensaios e tratados Moral social, Lições de direito constitucional, Noções e ciência da pedagogia, Tratado de sociologia e o Ensaio crítico sobre Hamlet.

\section{Filosofia moral}

As contribuições de Hostos à filosofia moral são tão importantes como seu pensamento educativo. De fato, muitos especialistas da educação consideram que não pode existir uma filosofia educativa sem uma base ética que sirva de fundamento à sua prática. No caso de Hostos, Chávez Rodríguez corrobora-o ao assegurar que "Fica evidente o elevado fim ético que - em última instância - lhe conferia à educação" (1995, p. 275), motivo pelo qual nesta seção vou esboçar algumas ideias da filosofia moral do pensador antilhano.

Da produção filosófica de Hostos, a que tem maior relevância é Moral social. Ele foi um pensador moralista que procurava em sua essência a moral e a ética pedagógica da educação (Ocampo 
López, 2004, p. 246). Com límpidas influências do krausismo espanhol, assim como do positivismo e, em menor grau, de Kant, Fichte, Hegel e Sêneca, Hostos aproxima-se à filosofia moral com admirável maestria.

Essa obra exibe o formidável ensaísta que era Hostos, além do original pensador que, se bem recebeu a influência das ideias filosóficas do momento histórico, não se amoldou a elas, mas as assimilou e as transformou, além de oferecer relevantes conceitos à história do pensamento filosófico-moral.

Moral Social está dividida em duas partes. Na primeira (que é a que agora interessa compreender), o autor desvenda as bases teóricas sobre as quais estão sustentados seus conceitos, pelo que podemos classificá-lo como um filósofo moral. Na segunda, ele aplica essas ideias a casos concretos e faz recomendações morais, razão pela qual pode ser chamado de moralista também. A primeira edição da obra foi publicada em 1888.

$\mathrm{Na}$ introdução, o filósofo declara que Moral Social é sua reação pela preocupação dos rumos que levava a civilização até então. Dessa forma, ele apresenta a dicotomia "civilização/barbárie" que tanto inquietou o pensador argentino Domingo Faustino Sarmiento. No entanto, sua aproximação com o assunto encaminhou-se numa outra direção. Hostos confessa estar convencido de que à altura de sua época (1888) o ser humano é já "adulto de razão" e inclusive "adulto de consciência" porque a razão, a consciência e o trabalho têm sido emancipados. Ele diz estar perplexo que ainda os instintos e as paixões aflorem sobre os princípios e os deveres.

O filósofo estava convencido de que a hipotética civilização do ser humano ainda não estava completa.
Proclama-o com clareza quando afirma que "Embaixo de cada epiderme social bate uma barbárie" (Hostos, 1969, v. 16, p. 98). Assim, com o incremento de uma moral social ele esperava corrigir essa "divergência". Pensava que as teorias formuladas até o momento não tinham sido eficazes, porque "a crise moral contínua patenteia a insuficiência dos motivos que teólogos, metafísicos e moralistas têm imputado a todas e cada um dos ramos da moral" (idem, p. 115). Givilização era para ele "racionalização", isto é, fazer-se mais racional. Hostos chega à conclusão de que "ser civilizado e ser moral é o mesmo" (idem, p. 106).

Hostos explica que os "órgãos" como ele os denomina - para alcançar o conhecimento das ideias morais são três: a razão, o sentido comum e a consciência. Ele aduzia que a razão era o meio para conhecer a realidade ou natureza moral (idem, p. 17). O sentido comum consistia em perceber diretamente os fenômenos que são perceptíveis aos sentidos corporais assim como as realidades morais (idem, p.16). Finalmente, a consciência é para Hostos "O órgão supremo da personalidade, na qual se unem como órgãos subordinados todos os organismos imateriais da natureza humana e onde se reflete e representa íntima e continuamente a individualidade" (idem, p. 19). Assim entendida, então, a consciência serve para fornecer o conhecimento imediato da natureza moral enquanto afeta a cada indivíduo na natureza.

Segundo Hostos, a moral social é a ligação de duas ciências: a ética e a sociologia. É evidente a influência do positivismo no fundamento dessa asseveração. Hostos, de maneira semelhante a Comte, aduzia que a moral 
social deve ser reconhecida como "a última ciência”.

Para nosso filósofo, todo ato que se efetue tem de passar pelo filtro do dever. Ele fundamenta a moral nas relações e deveres do ser humano na sociedade quando afirma que: "O fundamento dos deveres que a moral impõe está no conhecimento das relações que ligam o homem com a natureza geral ou com alguns aspectos particulares da natureza. E como a sociedade é um aspecto particular da natureza, o conhecimento dos deveres sociais se funda no conhecimento das relações do indivíduo com a sociedade" (idem, p. 109).

A sociedade desmembra-se no indivíduo, na família, no município, na região, na nação ou sociedade particular e na família de nações ou sociedade internacional.

Como se pode notar, a moral social estabelece as relações e os deveres que o indivíduo deve ter com cada um dos órgãos constitutivos da sociedade. Hostos tenta "demonstrar que não há moral social, senão enquanto há relações necessárias entre indivíduo e sociedade" (idem, p. 115). Exatamente por isso Hostos concebe uma estrita classificação "científica" das relações e dos deveres. Esse assunto levou o filósofo mexicano Antonio Caso a sustentar que "A base lógica da moral de Hostos é o conceito da eurritmia universal construído sobre a noção da lei natural. Para Hostos, como para Montesquieu, toda lei é "expressão necessária das relações das coisas"; e a lei moral, expressão, necessária também, da natureza física com o mundo social e moral" (idem, p. 218).

As relações que unem o indivíduo com a sociedade são: a necessidade, a gratidão, a utilidade, o direito e o dever. Hostos julga os deveres como essenciais na sua moral social, motivo pelo qual expõe uma interessante e original deontologia. Por um lado, Hostos diz que o freio da consciência é o dever; por outro, concede tanta importância ao dever que deduz que "Sem moral não há ordem e sem dever não há moral" (idem, p. 134-135). Quer dizer que os deveres são derivados de nossas relações com a sociedade, e ele os divide em dois grupos: os deveres genéricos e os deveres secundários.

Os deveres secundários estão subordinados e, ao mesmo tempo, originam e modificam os genéricos pela "influência do meio social em que atuam" (idem, p. 143). Ao dever genérico do trabalho subordinam-se os deveres de contribuição ao trabalho, o de fomento, o de patriotismo e o de subordinação. O dever de obediência tem como deveres secundários a submissão, a adesão e o acatamento à lei, a civilização, à razão e à consciência. O dever de sacrifício acarreta deveres secundários como a cooperação, união, abnegação, conciliação e coordenação. Por último, o dever de educação conduz aos deveres de instrução fundamental e de educação profissional.

De todos os deveres que Hostos assinala em sua obra, é "o dever dos deveres", de clara inspiração kantiana, o que sobressai aos demais. Hostos ilustra-o assim: "Há um dever que abrange a todos os demais; é o dever dos deveres. Consiste em cumprir todos, qualquer seja seu caráter, qualquer o momento que se apresente a ativar nossos impulsos ou a despertar nossa preguiça ou a convencer nossa razão ou a pedir sua sentença à consciência” (idem, p. 176). 
Hostos não para aqui em sua exposição dos deveres. Além dos mencionados, adiciona os deveres do ser humano com a humanidade (confraternidade, filantropia, cosmopolitismo e civilização) e alguns deveres complementares que divide em primários e secundários.

Como se pode observar, uma das maiores contribuições de Hostos à filosofia hispânica - tanto do ponto de vista prático quanto teórico - é sua filosofia moral. Isso tem sido reconhecido por prestigiosos historiadores da filosofia e do pensamento latino-ameri cano. Em um dos primeiros estudos sobre a filosofia na América, Francisco García Calderón sustentou que:

Depois de Bello, o mais destacado dos filósofos de América do Sul foi Eugenio de Hostos (sic), que nasceu em 1839. Ele não meramente expôs as ideias europeias, ele tinha seu próprio sistema, o qual desenvolveu em uma série de obras notáveis; foi mais um moralista que um metafísico, e seja em Santo Domingo ou Lima ou Santiago nunca cessou em seu esforço por reformar a educação e o direito. Os problemas sociais e morais não lhe permitiam descansar; tentou encontrar uma nova moralidade e uma nova sociologia. (1915, p. 272)

Devo destacar que Hostos propôs sua teoria ética desde e para a Nossa América. Ele foi um pensador com límpida consciência latino-americana. Hostos, sempre pensando no ser latino-americano, e em oposição ao escolasticismo imperante, deu-se à tarefa de formular e desenvolver uma teoria ética e moral, além da educativa que interpretarei na próxima seção, que contém uma moral social, uma moral natural e uma moral individual.

\section{Filosofia educativa}

Ao tentar apreender o pensamento educativo de Eugenio María de Hostos, pode ser adequado lembrar o julgamento do escritor venezuelano Rufino Blanco-Fombona quando refletiu em torno às implicações das ideias educativas do pensador e presidente da Argentina (1868-1874) Domingo Faustino Sarmiento e às de Hostos. Blanco-Fombona: "A preocupação do Sarmiento foi instruir ler à Argentina; a de Hostos ensinar a pensar a América" (1917, p. 181). Talvez nessa asseveração de Blanco-Fombona se possa compreender a dimensão continental e a profundidade do pensamento educativo do porto-riquenho.

A realidade é que, apesar de ter sido escritor, filósofo e político, a vocação cardeal de Hostos foi a de educador. Talvez por isso seja o único latino-americano que encontramos no livro Fifty Mayor Thinkers on Education: From Confucius to Dewey (Cinquenta grandes pensadores em torno da educação: de Confúcio a Dewey), da editora inglesa Routledge. O artigo sobre Hostos foi escrito pelos professores Ángel Villarini Jusino, da Universidade de Porto Rico, e Carlos Antonio Torre, da Universidade de Yale.

Em primeiro lugar, sinto a obrigação de explicar sucintamente o que entendo por filosofia educativa. Concebo a filosofia educativa como a visão e as ideias de um pensador sobre sua própria execução pedagógica. Isto é, o como (práxis) ele ou ela vai executar sua atividade de ensino, assim como o porquê 
(theoria) ou as razões e os conceitos que o levam a educar. Em palavras simples, a teoria e a prática são os elementos que constituem a filosofia educativa de um sujeito. No entanto, devo ressaltar que essa teoria e prática da pedagogia têm de sair da própria realidade individual e social tanto do educador quanto do educando. Como assevera Edward J. Power, "Sem importar como definamos a filosofia educativa, ela deve ser mais que aspiração social forte e desejo fraterno" (1996, p. 3). Em minha opinião, a filosofia educativa tem de provocar no mínimo uma transformação social e moral na prática de aprendizagem, o que não implica, de jeito nenhum, imposições de ideias preconcebidas. A final de contas, instruir a pensar, mais que o ensino de dados, deve ser o alvo de uma autêntica filosofia educativa ou não será eficaz. Como veremos, assim se configura a filosofia educativa hostosiana.

Além disso, pelo geral se confunde o termo em questão com o conceito filosofia da educação quando não são noções sinônimas. A filosofia da educação refere-se à reflexão filosófica e à indagação dos termos, processos e problemas próprios da educação, como, por exemplo, a liberdade do ensino e a finalidade da prática educativa. Portanto, a filosofia da educação é um saber filosófico, ainda que o expressado possa parecer tautológico. É um saber filosófico como são a filosofia da história e a filosofia política.

Para podermos compreender a filosofia educativa de Eugenio María de Hostos temos de nos perguntar o motivo pelo qual a educação foi tão indispensável para ele. As respostas podem ser diversas, no entanto a de maior relevância - em minha perspectiva - é que ele estava consciente que a maior parte dos países latino-americanos já tinha atingido a independência política, mas ainda precisava alcançar a emancipação mental, o que só podia advir por meio da educação. Efetivamente, durante o século XIX, depois de ter concluído as lutas pela independência política, a América Latina passa, primeiro, pelo processo de descolonização (1824-1853) para então iniciar sua organização política e social (1853-1885). Durante esse decurso, sobretudo o de organização, os hispano-americanos perceberam que, mesmo já libertos do cativeiro político e econômico da Espanha, todavia era imprescindível se libertar das ideias opressoras. Isto é, do mesmo modo precisavam da emancipação mental, como o percebeu o chileno Francisco Bilbao. Não obstante, segundo o filósofo mexicano Leopoldo Zea (1956, p. 30), daqui em diante a libertação teria de ser mais efetiva.

Era preciso emancipar-se da Espanha de modo mais profundo que o puramente formal da emancipação política. A emancipação mental da América espanhola devia ser a segunda fase. Uma emancipação que só podia obter-se por meio da educação. Era necessário prover aos hispano-americanos de novos hábitos e costumes, dos mesmos hábitos e costumes que tinham dado capacidades aos indivíduos que tinham criado as novas e poderosas nações; era indispensável transformar sua mente.

Consciente dessa situação, Eugenio María de Hostos arremete com potente voz ao dizer que:

Todos nossos povos de origem latina no continente americano, ar- 
rastados pela torrente tradicional que seguiam as velhas nacionalidades, têm se imbuído num sistema de pensamento que, como emprestado, não serve ao corpo de nossas sociedades juvenis.

Tem urgência de uma ordem intelectual que corresponda à força de sua idade, à elasticidade de seu regime jurídico, à extensão dos horizontes que têm pela frente, à potência do ideal que os dirige, e em vão se pedirá ao ensino preeminentemente literário a que a infância, a adolescência e a juventude vivem submetidos, que dê o regime intelectual que precisam. (1969, v. 12, p. 164-165)

Hostos, em tal caso, inicia um processo educacional nas mentes da juventude latino-americana, incluindo a oposição constante e contínua contra o escolasticismo até aquele momento imperante. Talvez seja essa a razão pela qual Hostos recomendava que a religião fosse ensinada exclusivamente nos seminários e nas casas e nunca nas escolas. As escolas de maneira nenhuma deviam ser sectárias. A respeito da atitude hostosiana contra o escolasticismo, Francisco Elías de Tejada ressaltou que:

Nisso não há maior novidade se se considera que Hostos foi um homem de seu século, apaixonado dos progressos da ciência e preocupado por superar as que ele estimava causas do atraso dos povos "das Espanhas". Aquele sentido realista, cativado dos progressos mecânicos e depreciativos pelas disputas teológicas, que informa tantas mentalidades do século XIX, é também seu gosto em questões de filosofia; daí seu contundente desprezo pelas fórmulas escolásticas, unidas inseparavelmente àquele passado, cuja carga constituía sua obsessão constante de lutador político e de pensador ideológico. (1949, p. 44)

Temos de lembrar que o escolasticismo foi uma doutrina teológica cristã da Idade Média que, inspirada em Aristóteles, alcançou seu máximo desenvolvimento com Tomás de Aquino. Seu método pedagógico estava baseado no princípio da autoridade (Magister dixit), a tentativa de reconciliar a fé com a razão, mas em que a fé sempre predomina (Philosophia ancilla theologiae), a repetição de textos e frases religiosas, sobretudo da Bíblia (auctoritates), e em que, em vista disso, a fonte fundamental do conhecimento era a revelação divina. Para fazer referência ao século XIX que é a época que agora nos interessa fala-se de um neoescolasticismo, mas suas linhas gerais continuam sendo as mesmas.

Hostos, então, dá origem à sua própria filosofia educativa com a intenção de edificar um novo mundo moral e intelectual. Javier Ocampo López vê em Hostos o paradigma do "pensamento antilhano da integração latino-americana e do fortalecimento da educação como único caminho do progresso deste povo que tem um futuro promissor" (2004, p. 246). As obras em que propõe seu pensamento educativo são os livros: Noções de pedagogia e História da pedagogia e nos discursos: "O propósito da Normal" e "A educação científica da mulher", dentre muitos outros.

Para Hostos, a educação não era uma coisa anódina, pelo contrário, considerava-a um direito e um dever. O dever de educação nos olhos de Hostos pressupunha a aprendizagem 
obrigatória. Porém, para que isso fosse possível, cada grupo da sociedade teria de contribuir com sua consumação. Os diferentes segmentos e suas obrigações educativas eram, segundo Hostos, as seguintes: a família (no lar) se encarregaria da educação infantil; o município, da escola fundamental; a província, das Escolas Normais, de artes e ofícios, institutos profissionais, escolas técnicas e politécnicas; a Nação (razão), da universidade; a sociedade internacional (consciência) do exame, espetáculo e exemplo da civilização universal.

Hostos com frequência teoriza em torno da educação, e quando se pergunta o como, o porquê e o para que dessa atividade, replica:

Instruir é educar a razão: educar a razão é dirigi-la ao seu funcionamento normal, com sujeição à ordem natural das suas funções; dirigi-la à ordem natural de suas funções é colocar a razão em capacidade de conhecer o como das coisas; o porquê das coisas, o para que das coisas: ou de maneira similar, o modo de ser das coisas; a razão da existência das coisas; o fim e o objetivo das coisas. O como e o porquê são da ciência especulativa; ou seja, da ciência que investiga na realidade o modo de ser e a razão de ser da realidade como ela é. O para que das ciências da aplicação, entre as quais a didática, a didascálica ou ciência da instrução, tem por destino o ensino do para que sirvam as verdades conhecidas, do para o que se podem aplicar os conhecimentos adquiridos.

O ensino do entendimento tem de alcançar do educando esses três resultados, ou não é ensino verda- deiro; ou, o que é igual, não instrui o entendimento como deve ser. (1969, v. 17, p. 225)

Quanto ao ensino verdadeiro, ele explica que é aquele que se desentende dos propósitos históricos, dos métodos parciais, dos procedimentos artificiais, e atende exclusivamente ao sujeito do conhecimento, que é a razão humana, e o objeto do conhecimento, que é a natureza. Essa feliz união, segundo ele, dará por fruto a verdade.

Em quanto à razão, o educador avalia que precisamente o objeto "capital da pedagogia" é "Educar a razão segundo a lei da razão", o que para ele significava conduzir o educando de "dentro para fora" e que quando esteja formado deixar que ele prossiga seu "livre desenvolvimento" (1969, v. 18, p. 11).

Afinal de contas, para Hostos o ensino tinha de ter como escopo a busca da verdade, porque para ele a escola precisa ser "o templo da verdade". De fato, uma das expressões mais célebres dele tem a ver com a verdade, o que se pode apreciar no seguinte trecho:

Dão-me a verdade, e eu os dou o mundo. Vocês, sem a verdade, vão destroçar o mundo, e eu, com a verdade, só com a verdade, reconstruirei o mundo quantas vezes vocês o tenham destroçado. E não vou dar somente o mundo das organizações materiais, darei o mundo orgânico, com o mundo das ideias, com o mundo dos afetos, com o mundo do trabalho, com o mundo da liberdade, com o mundo do progresso - para proferir o pensamento íntegrocom o mundo que a razão produz perduravelmente por cima do mundo natural. (1969, v.12, p.138) 


\section{Método de ensino}

O método de ensino pelo qual Hostos tinha preferência era o concêntrico. Isto é, o fundamentado nos processos mentais das crianças e suas próprias experiências. Ele não patrocinava, por exemplo, o método alemão e sueco - utilizado no Chile na época - porque não acreditava na memorização e no excesso de palavras por, quiçá, provocar uma confusão nas mentes dos educandos.

O seu era um método racional que tinha como fundamento a intuição, a indução, a dedução e a sistematização. Hostos fundamenta a intuição pela curiosidade das crianças e porque eles são como uns receptores que recebem e guardam ainda que não queiram ou saibam o que recebem ou retenham. A indução, porque a verdade não pode ser percebida de qualquer maneira. A dedução, porque a razão tem de considerar tudo a pequenos intervalos (pouco a pouco). A sistematização, porque a razão tem de unir as partes com o todo para, logo, ver a verdade que tem conhecido ou crê ter conhecido. Num esquema desenhado pelo estudioso da filosofia educativa hostosiana Leonides Santos y Vargas (1991, p. 35), e que eu tenho adaptado segundo o sistema escolar brasileiro, o sistema educativo de Hostos ficaria mais ou menos assim:

\begin{tabular}{|c|c|c|}
\hline Função mental & $\begin{array}{c}\text { Etapa de } \\
\text { desenvolvimento }\end{array}$ & Nível institucional \\
\hline INTUIC̣̃̃O & infância & ensino fundamental \\
\hline INDUÇÃO & adolescência & ensino médio \\
\hline DEDUC̣ãO & juventude & ensino médio \\
\hline SISTEMATIZAC̣ãO & maturidade & ensino superior \\
\hline
\end{tabular}

Deve-se chamar atenção para o fato de que, para Hostos, o importante não era a resposta correta, senão o processo mental apropriado. A final de contas, as intenções de Hostos eram, essencialmente, duas: em primeiro lugar, formar "homens verdadeiros" ou "completos" e, em segundo lugar, e para ele ainda mais importante, gerar seres livres ou independentes.

Apesar de outros pesquisadores terem interpretações diversas sobre o que Hostos queria dizer com "homens completos", ou melhor (como eu prefiro entender o conceito), "seres humanos completos", concordamos que ele se referia a uma formação integral. No seu ensaio "A educação contra o crime", ele o comenta desse modo:

Não temos necessidade de ensinar a ser sábios, pois, ensinarem a serem homens verdadeiros é suficiente para afastar o homem do vício e do crime. Mas nenhum educador poderá estar seguro do seu educando, se só o ensina a fazer uso da razão. Terá, se o quer pôr fora do alcance da maior parte das paixões perturbadoras, que ensinar também a fazer uso de sua sensibilidade e de sua voluntariedade. (1969, v. 13, p. 237)

Alguns estudiosos encontram no sentido dessa expressão a influência 
do teórico da educação suíço Johann Heinrich Pestalozzi (1746-1827). Eu, no entanto, reconheço de mais perto a influência do krausismo espanhol, sobretudo a de seu amigo e colega Francisco Giner de los Ríos (1839-1915) e sua Instituição Livre de Ensino. ${ }^{3}$

Sobre seu interesse em formar seres humanos livres, tenho de advertir, por estranho que pareça, que eu li antes a Paulo Freire que ao mesmo Hostos, principalmente se falamos em ler com profundidade. Cada vez que lia alguns textos de Hostos, mais semelhança encontrava nos dois. Em seu artigo "La pedagogía de la liberación en Eugenio María de Hostos", Ángel Villarini escreveu que:

Seu trabalho de síntese sobre os objetivos, a estrutura e o processo evolutivo do desenvolvimento humano que a educação está chamada a fomentar constitui provavelmente uma criação original e antecipa em muitos aspectos os intentos atuais das escolas pedagógicas como a educação baseada no cérebro, o construtivismo piagetiano, a perspectiva histórico-cultural vigoskiana e a pedagogia da liberação de Freire.

Em relação a esse mesmo ângulo, Leonides Santos y Vargas faz finca-pé no adiantado do pensamento de Hostos em semelhança com o conceito da conscientização que tanto Freire desenvolveu nas suas teorias e práticas educativas (1991,

3 O krausismo espanhol, que realmente foi a adaptação das ideias do alemão Karl Christian Friedrich Krause (1781-1832), tinha como objetivo a formação moral e educativa dos indivíduos para a consecução do "racionalismo harmônico. p. 30). Sobre a noção da conscientização em Freire, Luiz Gonzaga de Sousa está certo quando diz que:

A conscientização é mais do que saber o que se passa ao seu redor, é acima de tudo um processo histórico e neste sentido coloca Paulo Freire (1980) [1]: no ato mesmo de responder aos desafios que lhe apresenta seu contexto de vida, o homem se cria, se realiza como sujeito, porque esta resposta exige dele reflexão, crítica, invenção, eleição, decisão, organização, ação... Todas essas coisas pelas quais se cria a pessoa e que fazem dela um ser não somente adaptado à realidade e aos outros, mas integrado. É isto que Freire entende por conscientização. É o homem se descobrindo. É a luta para se descobrir a si próprio, interrogando-se e buscando respostas aos seus desejos e observações.

É imperativo clarificar que Hostos nunca empregou a palavra "conscientização", porém ele cunhou o vocábulo - em espanhol - conscifacción (do latim conscientia $=$ consciência e facere $=$ fazer), o que dá algo similar à palavra em questão. Em sua Moral Social, nosso filósofo esclarece que ele está lutando pela emancipação da mente colonizada da América e adverte que com esse termo ele quer dizer "proceder de menos consciência a mais consciência" ou "ao conjunto de atos voluntários de fazer-se mais consciente" (1969, v. 16, p. 17). Por isso, Hostos, segundo seu dizer, teve como propósito formar um "exército de professores que lutara contra a ignorância, contra a superstição, contra o cretinismo e contra a barbárie" (idem, 
v. 12, p. 132). Afinal de contas, o que o filósofo tinha como meta era:

Com, portanto, o amor à verdade e à justiça, tinha que inculcar-se no espírito das gerações educandas um sentimento poderoso da liberdade, um conhecimento consciencioso e radical da potência construtora da virtude, e um tão profundo, positivo e incomovível conhecimento do dever de amar a pátria, em tudo bem, por tudo bem e para tudo bem, que nunca por nunca resulte possível que a pátria deixara de ser a mãe das almas dos filhos nascidos em seu regaço santo ou dos filhos adotivos que trouxeram a seu seio o trabalho, a proscrição ou o perseguimento tenaz de um ideal. (idem, p. 133)

Não deixa de ser interessante conhecer alguns dos pensadores que exerceram influências nas ideias filosófico-educativas do pensador porto-riquenho. Em termos gerais, as principais influências no pensamento educativo de Hostos (Henríquez Ureña, 1994, p. 153-172) são:

- Froebel, com sua ênfase na escola materna para desenvolver as atividades e destrezas manuais no ensino.

- Pestalozzi, com a escola indutiva, baseada na observação e a experiência, em que as ciências têm um papel fundamental.

- Rousseau e sua escola intuitiva e objetiva.

- Francke e sua organização da escola em grande escala.

- Kant, no melhoramento da sociedade, por meio da perfeição dos indivíduos.
- Spencer, na dedução científica como preparação para a vida.

Outros veem a inspiração filosófica de sua teoria educativa primordialmente no positivismo evolutivo de Comte e Spencer e no idealismo de Krause (Villarini; Torre, 2001, p. 149). Eu considero que na concepção moral ele teve uma grande influência do positivismo, entretanto, na sua teoria educativa o influxo principal é do krausismo espanhol. Fique claro que o positivismo de Hostos não é exatamente o positivismo europeu, ele insere-se melhor no positivismo sui generis latino-americano, como o propõe o pensador cubano Pablo Guadarrama González ao esclarecer que:

Se alguma coisa teve de sui generis o positivismo latino-americano foi não identificar-se com a tese sobre o possível debilitamento da filosofia e praticamente sua dissolução com o auge das ciências particulares. Em todo momento, nos positivistas latino-americanos se apreciou uma alta consideração pelo saber filosófico, pelo que fundamentaram o caráter metodológico e da concepção geral do mundo que acompanha sempre a filosofia em correspondência permanente com o desenvolvimento das ciências particulares, sem que signifique um atentado contra seu objeto de reflexão. (2004, p. 214)

Ainda assim, mencionar as influências no pensamento de Hostos não constitui de maneira alguma desconhecer suas admiráveis contribuições à educação de Nossa América. 
A modo de conclusão, comentarei seu discurso "O propósito da Normal", que é um dos escritos hostosianos mais importantes pelo seu conteúdo filosófico-educativo, além de ser um magnífico padrão de seu domínio da oratória. De fato, o mesmo é a alocução lida na cerimônia de formatura dos primeiros professores normalistas dominicanos em 1884. Nele, Hostos expõe as ideias filosóficas que sustentavam sua visão pedagógica. O que pretendo fazer é um resumo de seu pensar educativo examinando as ideias contidas nessa obra.

Hostos estabeleceu a Escola Normal na República Dominicana em 1879. Seu interesse era despojar o educando das reminiscências do escolasticismo que ainda estavam entroncadas nos sistemas educativos de América e delinear suas novas ideias. Seu propósito era como antes estabeleci - contribuir com a emancipação mental de nossos povos.

Nesse discurso, Hostos quer responder aos que impugnam, atacam e inclusive escarnecem de sua teoria educativa simplesmente porque não a entendem. Mas ele está consciente de que tem prevalecido, pelo que se sente satisfeito. Para exemplificar sua placidez, narra a "alegoria da alpaca andina”, como bem a nomeou o filósofo colombiano Carlos Rojas Osorio. Pelo ilustrativo dela e por ser um fino arquétipo da força criativa de Hostos vou reproduzi-la em sua totalidade:

Uma vez, nos Andes soberanos, por não se sabe que extraordinária sucessão de esforços, tinha logrado subir ao penúltimo pico da cúspide da desolada geleira do Planchón, uma alpaca da cor tão pura como a não medida lâmina de gelo que lhe servia lhe de pedestal. Descendo pela vertiginosa ladeira da geleira, e mergulhando-se nos côncavos seios da terra com todo o fragor dos trovões repetidos mil vezes pelos ecos subterrâneos, as torrentes furiosas azotavam o bloco onde a alpaca se asilava. As ondas a sacudiam, as espumas a salpicavam, os estrondosos trovões a ameaçavam, e a tímida alpaca não temia.

Embaixo do cume, ao pé da geleira, uma turba de doentes que tinham ido procurar a cura de seus males ou de suas paixões naquela saudável desolação, entretinha-se contemplando a angustiosa luta entre a fraca andícola e os fortes Andes; e, como sempre que os homens se entretêm, uns zombavam da fraca, os outros celebravam com risadas das irracionais mofas, uns lançavam pedras que não podiam alcançar ao inacessível pequeno animal, aqueles tentavam acossá-lo com suas vociferações, algum se compadecia, só uns levavam para si o exemplo que ele lhe dava, e todos desejavam que chegasse o desenlace qualquer que esperavam.

Enquanto isso, a alpaca solitária, alheia aos gritos e risos dos homens, impassível pelo barulho e pelo perigo, procurando um ponto de apoio numa aresta do bloco do gelo petrificado que coroava a geleira, e depois de cair uma e mais vezes, por fim alcançou subir se ao único resguardo desse deserto desolado de gelo. Então, experimentado pela primeira vez o perigo de morte que tinha percorrido, e ouvindo pela primeira vez os vociferantes que o tinham acossado, dirigiu um olhar plácido aos homens, às tor- 
rentes desenfreadas e ao abismo que o tinham tentado jogar, fixou o olhar no espaço imenso, e percebendo sem dúvida quão frágil são os seres mortais na extensão imortal da natureza, transmitiu a seus olhos expressivos a cintilante expressão de gratidão que a todo ser vivente comove no instante de sua salvação, e dirigindo outro olhar sem rancor às forças naturais e aos homens que o tinham acossado, por invisíveis veredas se encaminhou serenamente a seu destino. (1969, v. 12, p. 129-130)

Para terminar a defesa que faz do seu próprio trabalho pedagógico-administrativo, finaliza dizendo que, "Na alma de todo ser racional que tem alcançado salvar as dificuldades de uma obra transcendental, se manifesta o mesmo fenômeno que observei na alpaca desencaminhada dos Andes. Acima de toda paixão detestável levanta-se no fundo o sentimento da gratidão. Eu a sinto profundamente, e a proclamo em voz alta ante vocês" (idem, p.131).

Nesse discurso, Hostos faz uma síntese das concepções que sustentam sua filosofia educativa. Suas ideias têm origem nos princípios científicos e morais pelos quais ele advogava. Princípios apoiados fundamentalmente na razão. Para justificar seu sistema ele declara que "Para que a República convalescesse, era indispensável estabelecer uma ordem racional nos estudos, um método razoado no ensino, a influência dum princípio harmonizador no professorado, e o ideal dum sistema superior a todo outro, com o propósito mesmo da educação comum" (idem, ibidem).

A intenção didática hostosiana era a formação do ser humano comple- to e a obtenção de sua liberdade. Para alcançá-lo, a razão tem de prevalecer sobre a vontade. A razão é fundamental para Hostos, já que somente através dela o ser humano pode conseguir o trinômio: bem, verdade, liberdade. Mas, como chegar até lá? Hostos responde que:

Só dum modo; o único que tem querido Natureza que seja médio universal da formação moral do ser humano: desenvolvendo a razão; articularei muito melhor, dizendo a racionalidade; ou seja, a capacidade de razoar e de relacionar, de idear e de pensar, de julgar e conhecer que só o homem, entre todos os seres que povoam o Planeta, tem recebido como caráter distintivo, eminente, excepcional e transcendente. (idem, p. 133-134)

Ao pensar que a capacidade de razoar livremente tem se mutilado, Hostos contrapõe-se tanto ao ensino empírico como ao clássico porque, segundo ele, o empirismo prescinde da razão e a instrução clássica amputa a razão (idem, p. 137). Dessa maneira, refere-se ao escolasticismo como "monstruoso" e como "eunuco", ao classicismo. Em um parágrafo em que sintetiza o que para ele é o ensino verdadeiro, ilustra que é aquele que atende "exclusivamente ao sujeito do conhecimento, que é a razão humana e o objeto do conhecimento, que é a natureza" (idem, p. 137-138). Afinal, o verdadeiro conhecimento é a busca da verdade.

Pondero que foi pela profundidade das ideias contidas nesse discurso que o célebre filósofo mexicano Antonio Caso o considerou "a obra-mestra do 
pensamento moral independente na América espanhola" (1939, p. 216). Da mesma maneira creio que o porto-riquenho Eugenio María de Hostos ganhou uma digna posição na história da filosofia educativa da América Latina pelo que ao menos lhe devemos conhecer e apreciar suas ideias.

Sinto o dever de finalizar minhas considerações em torno do pensamento educativo de Hostos esclarecendo que, quando ele fala de homens, ele fala dos homens e das mulheres, ainda que às vezes use o termo seres humanos como deve ser. $\mathrm{O}$ que de jeito nenhum quer dizer que ele não tivesse viva memória do antifeminismo tradicional. Pelo contrário, Hostos incansavelmente travou luta, sobretudo no Chile, em benefício da educação das mulheres. Nos seus discursos sobre "A educação científica da mulher", ele revelou estar convencido de que "A razão não tem sexo, e é a mesma faculdade com suas mesmas operações e funções no homem e na mulher (1969, v. 12, p. 28). É por esse motivo que, segundo ele, "A mulher não tem deveres diferentes que o homem. Varão ou fêmea, o ser racional tem o dever de adaptar seus meios ao fim da existência, e nada mais" (idem, p. 46).

Esses discursos ministrados na Academia de Belas Letras de Santiago de Chile em 1873 tiveram como efeito que as mulheres chilenas fossem admitidas na universidade, o que nunca antes havia acontecido. No Chile, além disso - como dado curioso - , sugere também escolas noturnas, nas prisões, para policiais, marinheiros, soldados, de artes, profissionais, comércio e náuticas, o que revela que ele concebia que a educação estivesse disponível para todos os indivíduos da coletividade social. Ainda mais importante, fico com a esperança de que pelo que foi expresso nestas reflexões se possa compreender que sua teoria educativa possuía visão de futuro.

\section{Referências bibliográficas}

BLANCO-FOMBONA, Rufino. Grandes escritores de América. Madrid: Renacimiento, 1917.

CARvalho, Jose Murilo de. Pontos e bordados: escritos de história e política. Belo Horizonte: UFMG, 1998.

CASO, Antonio. La filosofía moral de Hostos. In: COMISIÓN PRO CELEBRACIÓN DEL GENTENARIO. América y Hostos. La Habana: Cultural, 1939. p. 209-222.

CHÁVEZ RODRÍGUEZ, Justo A. La labor educativa de Eugenio María de Hostos. In: LÓPEZ, J.C. (Org.) Hostos: sentido y proyección de su obra en América. San Juan: IEH; EUPR, 1995. p. 273-284.

DÍAZ DE TEJADA, Francisco. Las doctrinas políticas de Eugenio María de Hostos. Madrid: Gultura Hispánica, 1949.

DORELLA, Priscila Ribeiro. Silvio Julio de Albuquerque Lima: um precursor dos estudos acadêmicos sobre a América Hispânica no Brasil. Dissertação (Mestrado) - Programa de Pós-Graduação, Departamento de História, Faculdade de Filosofia e Ciências Humanas, Universidade Federal de Minas Gerais, 2006.

GARGía CALDERÓN, Francisco. Latin America: Its rise and progress.New York: Charles Scribner's Sons, 1915.

GUADARRAMA GONZÁlEZ, Pablo. Hostos y el positivismo sui géneris latinoamericano. Revista Historia de la Educación Latinoamericana, v. 6, p. 209-234, 2004.

GURGEL, Rodrigo. O Brasil precisa descobrir a cultura latino-americana. Storm-Magazine. Disponível em: <http://www. storm-magazine.com/novodb/arqmais. php?id $=113 \& \sec =\& \sec n=>$. Acesso em: 2 mar. 2010. 
GUTIÉRREZ LABOY, Roberto. Eugenio María de Hostos: precursor de la bioética en América Latina. Santo Domingo: Editorial de la Biblioteca Nacional Pedro Henríquez Ureña, 2010.

HENRÍQUEZ UREÑA, Salomé. Las ideas pedagógicas de Hostos y otros escritos. Santo Domingo: Secretaría de Estado de Educación, Bellas Artes y Cultos, 1994.

HOSTOS, Eugenio María de. Obras completas. 2. ed. San Juan: Coquí, 1969. 20 v.

OCAMPO LÓPEZ, Javier. Eugenio María de Hostos (1839-1903): sus ideas americanistas y educativas para la formación de los maestros. Revista Historia de la Educación Latinoamericana, v. 6, p. 235-248, 2004.

POWER, Edward J. (1996). Educational Philosophy: A History from the Ancient World to Modern America. New York: Garland.

SANTOS Y VARGAS, Leonides. El pensamiento filosófico-educativo de Eugenio María de Hostos. In: HOSTOS, E. M. de. Ciencia de la pedagogía (nociones e historia). San Juan: ICPR; EDUPR, 1991. p. 21-40.

SOUSA, Luiz Gonzaga de.Economia, política e sociedade. 2006. Disponível em: < http://www. eumed.net/libros/2006a/lgs-eps/> . Acesso em: 1 mar. 2010.

VILLARINI JUSINO, Ángel A. La pedagogía de la liberación en Eugenio María de Hostos. Projecto para el desarrollo de destrezas del pensamiento. Disponível em: <http:// generales.uprrp.edu/pddpupr/materiales. htm >. Acesso em: 28 fev. 2010.
VILLARINIJUSINO, Ángel; TORRE, Carlos. A. Eugenio María de Hostos, 1839-1903. In: PALMER, J. A. (Org.). Fifty Major Thinker on Education, From Confucius to Dewey. London: Routledge, 2001. p. 146-154.

ZEA, Leopoldo. Esquema para una historia de las ideas en Iberoamérica. México: Imprenta Universitaria, 1956.

ROBERTO GUTIÉRREZ LABOY é doutor em filosofia, grau conferido pela Universidade de Rutgers, em Nova Jersey. Atualmente éprofessor titular de Ciências Humanas na Universidade de Porto Rico, campus universitário de Rio Pedras. Seus mais importantes livros são: Pensar y entender a Hostos, Ética a Ana Laura: hacia una ética humanista e La fragilidad humana y otros ensayos: reflexiones humanísticas. No ano acadêmico 2008-2009, a Universidade de Porto Rico outorgou-lhe a distinção de Catedrático de Honra Eugenio María de Hostos. $\mathrm{O}$ autor pode ser contatado pelo seu site http://www.drgutierrezlaboy.com ou no endereço: Facultad de Estudios Generales/Departamento de Humanidades/P.O. Box 23323/San Juan, P.R. 00931-3323.

E-mail:rgutierrez@alumni.rutgers.edu

Recebido em julho de 2010 Aprovado em novembro de 2010 


\section{A filosofia educativa de Eugenio María de Hostos}

$\mathrm{O}$ artigo discorre sobre as contribuições do filósofo porto-riquenho Eugenio María de Hostos à filosofia educativa e moral latino-americana, mas que pouco se conhece no Brasil. Hostos, que foi um dos principais filósofos e educadores do século XIX, propôs uma teoria educativa inovadora para as nações da América Latina. Sua filosofia educativa abrangia a finalidade conscienciosa de erigir um novo mundo moral e intelectual que serviria ao fundamento educativo que se precisava com urgência. Para ele, a educação era um direito e um dever tanto para os homens como para as mulheres, já que pensava que a razão não tinha sexo. $\mathrm{O}$ pensador deu ênfase ao essencial de educar a razão no processo pedagógico. Seu propósito era gerar seres livres e independentes, aptos a pensar por eles mesmos. Além disso, preocupado com a dicotomia "civilização/barbárie", apresentou um pensar ético que culminou numa moral social em que "o dever dos deveres" fosse pedra angular.

Palavras-chave: Hostos; filosofia educativa; ética; história da América

\section{The Eugenio María de Hostos' educational philosophy}

This article examines the contributions of the Puerto Rican philosopher Eugenio María de Hostos to educational philosophy and morality in Latin America but who is little known in Brazil. Hostos, who was one of the leading philosophers and educators of the nineteenth century proposed an innovative educational theory for those countries. His educational philosophy em- 
braced the conscious rationale for erecting a new moral and intellectual world that would serve the educational foundation that was urgently required. For him, education was both a right and a duty for men and women because, as he states, reason has no sex. The thinker emphasized how crucial was to educate the reason in the educational process. Its purpose was to bring into being free and independent individuals, capable of their own judgment. Even more, concerned by the dichotomy civilization/barbarism he presented an ethical thinking that culminated in a moral society where "the duty of duties" was the keystone.

Key words: Hostos; educational philosophy; ethics; Latin America history

\section{La filosofía educativa de Eugenio María de Hostos}

En este ensayo se exponen las contribuciones del filósofo puertorriqueño Eugenio María de Hostos a la filosofía educativa y moral latinoamericana, pero que poco se conocen en el Brasil. Hostos, uno de los principales filósofos y educadores del siglo XIX, propuso una teoría educativa innovadora pensando en las naciones de la América Latina. Su filosofía educativa contenía la finalidad consciente de constituir un nuevo mundo moral e intelectual que serviría al cimiento educativo que se necesitaba con urgencia. Para él, la educación era un derecho y un deber tanto para los hombres como para las mujeres debido a que opinaba que la razón no tenía sexo. El pensador dio énfasis a lo esencial de educar la razón en el proceso pedagógico. Su propósito era formar seres libres e independientes, aptos para pensar por ellos mismos. Además, preocupado por la dicotomía "civilización/barbarie" presentó un pensar ético que culminó en una moral social en la cual "el deber de los deberes" fuera la piedra angular.

Palabras claves: Hostos; filosofía educativa; ética; historia de América 